\title{
Design Optimization and Performance Evaluation of the Open-Graded Friction Course with Small Particle Size Aggregate
}

\author{
Hao Fu, Chaohui Wang ${ }^{(D)}$, GongXin Yu, Qian Chen, and Luqing Liu \\ School of Highway, Chang'an University, Xi'an 710064, China \\ Correspondence should be addressed to Chaohui Wang; wchh0205@chd.edu.cn and Luqing Liu; 2020021082@chd.edu.cn
}

Received 21 October 2020; Revised 25 January 2021; Accepted 3 February 2021; Published 17 February 2021

Academic Editor: Nicola Baldo

Copyright $\odot 2021 \mathrm{Hao} F u$ et al. This is an open access article distributed under the Creative Commons Attribution License, which permits unrestricted use, distribution, and reproduction in any medium, provided the original work is properly cited.

\begin{abstract}
This study aims to optimize the bonding performance between the wearing course and the used pavement or the underlying layer and further improve the service quality and durability of the open-graded friction course with small particle size aggregate (ultrathin OGFC). The ultrathin OGFC including waterborne epoxy resin emulsified asphalt (WEA) bonding layer and opengraded asphalt concrete with $9.5 \mathrm{~mm}$ nominal maximum aggregate size gradation was optimized. The construction timing of the open-graded asphalt mixture was determined. The road performance, wear resistance, and interlaminar bonding durability of the ultrathin OGFC were comprehensively evaluated. The results show that, based on the basic properties of the open-graded asphalt mixture, its asphalt aggregate ratio is recommended to be $5.0-5.5 \%$. Based on interlaminar shear strength, it is recommended that the open-graded asphalt mixture is paved immediately after WEA bonding material was sprayed, and the bonding layer does not spread aggregate. The WEA containing 20\% waterborne epoxy resin (WER) is recommended as bonding layer for the ultrathin OGFC, and the optimized spraying amount is $1 \mathrm{~kg} / \mathrm{m}^{2}$. The ultrathin OGFC has good antisliding, drainage, and wear resistance properties. The interlaminar bonding performance, water stability, and durability of WEA bonding layer are obviously better than those of high viscosity asphalt (HVA) and SBS-modified asphalt. The WEA bonding layer can better resist interlaminar shear failure and improve the service quality and service life of the ultrathin OGFC.
\end{abstract}

\section{Introduction}

The open-graded friction course with small particle size aggregate (ultrathin OGFC) can effectively repair the early minor damages and surface functions of the used pavement and improve driving safety under the slippery condition $[1,2]$. Compared with microsurfacing, the ultrathin OGFC has certain structural strength and drainage function. It is more conducive to its resistance to the comprehensive damage of complex environments such as high temperature, rainy, and heavy load. The ultrathin OGFC can not only be used as a preventive maintenance measure to repair the damage of the used pavement but also be used for the wearing course of new pavement [3].

Luo et al. used epoxy asphalt as binder, the ultrathin OGFC with the nominal maximum aggregate sizes of $4.75 \mathrm{~mm}$ and $9.5 \mathrm{~mm}$ was designed, and results showed superior overall performance of the ultrathin epoxy asphalt
OGFC compared to conventional ultrathin OGFC [2]. A cold-mixed ultrathin porous friction course with waterborne epoxy resin/polyurethane composite emulsified asphalt was prepared by Yang et al. and results showed that when the rainfall intensity was $35 \mathrm{~mL} / \mathrm{s} / \mathrm{m}^{2}$, the British pendulum numbers of the wearing course were 66-73 BPN [3]. Coleri et al. obtained the X-ray computed tomography (CT) images of OGFCs' full-scale accelerated pavement rutting test (APT) specimens. The change of pore structure and water seepage of the wearing course was studied, and the rutting formation mechanism was analyzed by image processing technology $[4,5]$. Wang et al. found that the fatigue and permanent deformation damage of flexible pavement can be effectively reduced after paving the ultrathin OGFC [6]. Pasquini et al. studied the mechanical properties of rubber asphalt OGFC, such as stiffness, fatigue, and permanent deformation [7]. Eck et al. found that porous friction course can improve driving safety on rainy days and improve the water quality of 
the rainwater flowing through the pavement. On rainy days, the pollutants of suspended matter and particulate matter in the runoff of porous friction course are reduced by at least $90 \%$ compared with traditional asphalt pavement $[8,9]$. Zeng et al. prepared three kinds of wearing course, dense-graded AC-13C, semiopen-graded NovaChip type-C, and opengraded OGFC-13. The OGFC-13 showed the best structural depth and permeability coefficient, but its interlaminar shear strength was poor [10]. In conclusion, the current relevant researches mainly focused on the mixture proportion optimization, binder performance improvement, and road performance evaluation of the ultrathin OGFC [11-15]. There is a lack of systematic study on the interlaminar bonding performance and its durability between the wearing course and the used pavement or the underlying layer. Due to the poor interlaminar bonding performance, the ultrathin OGFC was often damaged by interlaminar displacement, peeling, and cracking. Meanwhile, the water damage caused by insufficient interlaminar waterproof performance can accelerate the ultrathin OGFC damage [10]. Therefore, it is necessary to further improve the interlaminar waterproof bonding system of the ultrathin OGFC. The interlaminar waterproof bonding materials include modified asphalt, dilution asphalt, modified emulsified asphalt, and epoxy resin [16]. Compared with hot asphalt, modified emulsified asphalt can be sprayed under normal temperature, which has the advantages of environmental protection, energy saving, convenient construction, and safety. Modified emulsified asphalt is a widely studied and applied interlaminar waterproof bonding material. The waterborne epoxy resin emulsified asphalt (WEA) forms a three-dimensional network structure through the physical-chemical cross-linking of waterborne epoxy resin (WER) and curing agent, which retains the excellent thermal stability, bonding strength, and waterproof performance of epoxy resin and has good construction advantages of emulsified asphalt [17-22]. In the field of road engineering, many studies have been carried out on WEA as binder for microsurfacing and cold mix asphalt mixture [23-26]. At the same time, WEA as waterproof bonding material used in cement concrete bridge deck pavement has also carried out some research. Liu et al. applied WEA to the waterproof bonding layer of bridge deck pavement, and the research results showed that its shear strength, pull-out strength, and shear fatigue performance were better than high those of viscosity asphalt and SBSmodified asphalt $[27,28]$. The above studies showed that WEA has good interlaminar bonding and water stability performance. However, there are few related researches on the application of WEA to the bonding layer between the ultrathin OGFC and the used pavement or the underlying layer.

Based on this, WEA was selected as the interlaminar bonding material for the ultrathin OGFC. The bonding layer and the construction timing of the open-graded asphalt mixture were optimized. The road performance, wear resistance and interlaminar bonding durability of the ultrathin OGFC were comprehensively evaluated. It is of great significance in improving the application effect of the ultrathin OGFC, ensuring road traffic safety and extending road service life. It lays a foundation for the further application of the ultrathin OGFC in the hot and wet areas.

\section{Test Materials and Methods}

2.1. Raw Materials. The ultrathin OGFC prepared in this paper includes WEA bonding layer and $2-2.2 \mathrm{~cm}$ opengraded asphalt concrete with $9.5 \mathrm{~mm}$ nominal maximum aggregate size gradation. The WEA was self-made by the scheme of emulsification first and then modification. High viscosity asphalt (HVA) and SBS-modified asphalt were selected as the control group of interlaminar bonding materials. The main materials used for the open-graded asphalt mixture include HVA, basalt aggregate (the content of $\mathrm{SiO}_{2}$ is $45-52 \%$ ), and limestone mineral filler. The technical indexes of raw materials meet relevant technical requirements of technical specification for permeable asphalt pavement (CJJ/T 190-2012), China [29]. The main technical indexes of each material are shown in Tables 1-5.

2.2. Gradation. At present, the nominal maximum size of the aggregate used in preventive maintenance wearing course was less than $10 \mathrm{~mm}$. The common ultrathin OGFC can be divided into two types, the coarse type mainly consists of the aggregate with a particle size of $4.75-9.5 \mathrm{~mm}$, and the fine type mainly consists of the aggregate with a particle size of $2.36-4.75 \mathrm{~mm}$. In order that the friction course has better drainage performance and adapt to the damage effect of large traffic volume and heavy load, the coarse type gradation was selected. Referring to the gradation of PAC-10 mixture recommended in CJJ/T 190-2012, China [29], and relevant research results [1-4], the small particle size aggregate open-graded asphalt mixture was determined, and the specific gradation is shown in Table 6 . The asphalt aggregate ratio was initially set at five levels of $4.5 \%, 5 \%, 5.5 \%$, $6 \%$, and $6.5 \%$.

2.3. Test Methods. Firstly, the basic properties of the opengraded asphalt mixture were tested to determine its asphalt aggregate ratio. The WEA was selected as the interlaminar bonding material, and the bonding layer for the ultrathin OGFC was optimized by testing the interlaminar shear strength. WEA has been compared with HVA and SBSmodified asphalt interlaminar bonding materials. The construction timing of the open-graded asphalt mixture was determined. The road properties of the ultrathin OGFC were studied. Finally, the wear resistance of the ultrathin OGFC was evaluated by loading wear test, and interlaminar bonding durability of the ultrathin OGFC was determined.

\subsubsection{Test Method of the Open-Graded Asphalt Mixture Basic} Properties. According to the relevant requirements in Standard Test Methods of Bitumen and Bituminous Mixtures for Highway Engineering (JTG E20-2011), China [30], Schellenberg binder drainage test, Cantabro test, percent air voids test, and Marshall stability test were carried out. The maximum and minimum asphalt aggregate ratio of small 
TABLE 1: The main technical indexes of WEA.

\begin{tabular}{|c|c|c|c|c|c|c|c|c|}
\hline Items & $\begin{array}{l}\text { Particle } \\
\text { charge }\end{array}$ & $\begin{array}{l}\text { Residue on the } \\
1.18 \mathrm{~mm} \text { sieve }(\%)\end{array}$ & $\begin{array}{c}\text { Solid } \\
\text { content }(\%)\end{array}$ & $\begin{array}{l}\text { Surface dry } \\
\text { time }(\mathrm{h})\end{array}$ & $\begin{array}{l}\text { Dry time } \\
\text { (h) }\end{array}$ & $\begin{array}{c}\text { Heat } \\
\text { resistance }\left({ }^{\circ} \mathrm{C}\right)\end{array}$ & $\begin{array}{c}\text { Impermeability } \\
(0.4 \mathrm{MPa}, \\
30 \mathrm{~min})\end{array}$ & $\begin{array}{c}\text { Tensile } \\
\text { strength }(\mathrm{MPa})\end{array}$ \\
\hline $\begin{array}{l}\text { Test } \\
\text { value }\end{array}$ & Cationic & $\leq 0.1$ & $50 \pm 2$ & $<1$ & $<3$ & 163 & Impervious & $2.1-2.5$ \\
\hline
\end{tabular}

TABLe 2: The main technical indexes of high viscosity asphalt.

\begin{tabular}{lccccccc}
\hline Items & $\begin{array}{c}\text { Penetration } \\
\left(25^{\circ} \mathrm{C}, 0.1 \mathrm{~mm}\right)\end{array}$ & $\begin{array}{c}\text { Softening } \\
\text { point }\left({ }^{\circ} \mathrm{C}\right)\end{array}$ & $\begin{array}{c}\text { Ductility } \\
\left(5^{\circ} \mathrm{C}\right)(\mathrm{cm})\end{array}$ & $\begin{array}{c}\text { Flash point } \\
(\mathrm{COC})\left({ }^{\circ} \mathrm{C}\right)\end{array}$ & $\begin{array}{c}\text { Elastic recovery } \\
\left(25^{\circ} \mathrm{C}, 10 \mathrm{~cm}\right)(\%)\end{array}$ & $\begin{array}{c}\text { Dynamic } \\
\text { viscosity }\left(60^{\circ} \mathrm{C}\right) \\
(\text { Pa.s })\end{array}$ & $\begin{array}{c}\mathrm{TFOT}\left(163^{\circ} \mathrm{C}, 5 \mathrm{~h}\right) \\
\text { Mass } \\
\text { loss }(\%)\end{array}$ \\
$\begin{array}{l}\text { Penetration } \\
\text { ratio }(\%)\end{array}$ \\
\hline $\begin{array}{l}\text { Test } \\
\text { value }\end{array}$ & 62.8 & 87 & 37 & 290 & 91 & 191000 & 0.2 \\
\hline
\end{tabular}

TABLE 3: The main technical indexes of SBS-modified asphalt.

\begin{tabular}{lcccccc}
\hline Items & $\begin{array}{c}\text { Penetration } \\
\left(25^{\circ} \mathrm{C}, 0.1 \mathrm{~mm}\right)\end{array}$ & Softening point $\left({ }^{\circ} \mathrm{C}\right)$ & Ductility $\left(5^{\circ} \mathrm{C}\right)(\mathrm{cm})$ & \multicolumn{3}{c}{ TFOT $\left(163^{\circ} \mathrm{C}, 5 \mathrm{~h}\right)$} \\
Mass loss $(\%)$ & Penetration ratio $(\%)$ & Ductility $\left(5^{\circ} \mathrm{C}\right)(\mathrm{cm})$ \\
\hline Test value & 53 & 72.5 & 33 & -0.368 & 67.9 & 19.9 \\
\hline
\end{tabular}

TABLe 4: The main technical indexes of basalt aggregate.

\begin{tabular}{lccccc}
\hline Items & Crushed stone value (\%) & Polished stone value (BPN) & Acicular content (\%) & Weared stone value (\%) & Sturdiness (\%) \\
\hline Test value & 12 & 53 & 5 & 13 & 3 \\
\hline
\end{tabular}

TABle 5: The main technical indexes of limestone mineral filler.

\begin{tabular}{lccccc}
\hline Items & Apparent density & Appearance & Plasticity index (\%) & Moisture content (\%) & Hydrophilic coefficient \\
\hline Test value & 2.60 & No agglomerates and lumps & 2.6 & 0.3 & 0.5 \\
\hline
\end{tabular}

TABLE 6: The gradation of the mixture.

\begin{tabular}{lcccccccc}
\hline Standard test sieves size $(\mathrm{mm})$ & 9.5 & 4.75 & 2.36 & 1.18 & 0.6 & 0.3 & 0.15 & 0.075 \\
\hline Mass passing percentage $(\%)$ & 100 & 33 & 18 & 10.5 & 8.5 & 7.5 & 6.5 & 5.5 \\
\hline
\end{tabular}

particle size aggregate open-graded asphalt mixture were determined according to the binder drainage mass loss and Cantabro mass loss [2]. Furthermore, the asphalt aggregate ratio was optimized according to percent air voids, percent connected air voids, and Marshall stability of Marshall test specimens. Five specimens were tested in each group, and the average of three valid test results was reported.

\subsubsection{Test Method of the Bonding Layer Optimization}

(1) Test Method of Aggregate Spreading Scheme Optimization. At present, the interlaminar shear strength is mainly used to evaluate the interlaminar bonding performance and shear resistance of waterproof bonding layer $[27,28]$. To determine the effect of spreading aggregate on the bonding performance of the bonding layer, the friction course composite structure specimens composed of $3 \mathrm{~cm} \mathrm{AC-13}$ asphalt mixture + bonding layer (including spreading aggregate and nonspreading aggregate) $+2 \mathrm{~cm}$ small particle size aggregate open-graded asphalt mixture $(30 \mathrm{~cm} \times 30 \mathrm{~cm})$ were prepared, and their interlaminar shear strength was tested. To evaluate the high-temperature bonding performance of the bonding layer, the interlaminar shear strength was tested at $25^{\circ} \mathrm{C}, 40^{\circ} \mathrm{C}$, and $60^{\circ} \mathrm{C}$. In this experiment, the content of WER in WEA was 20\%, and its spraying amount was $1 \mathrm{~kg} /$ $\mathrm{m}^{2}$. The SBS-modified asphalt and HVA were selected as the contrast interlaminar bonding materials, and their spraying amount was $1.8 \mathrm{~kg} / \mathrm{m}^{2}$. According to JTG E20-2011, China [30], the composite structure specimens were formed. First, the $3 \mathrm{~cm} \mathrm{AC-13}$ asphalt concrete pavement was formed, cured, and demoulded. Second, the specified mass of interlaminar bonding material was sprayed on its surface. The $4.75-9.5 \mathrm{~mm}$ basalt aggregate was quickly and evenly 
distributed, with coverage of $60 \%$ (the specimen with spreading aggregate). The composite structure specimens with spreading aggregate and nonspreading aggregate were cured under the same conditions. After WEA was emulsified and dried, the $2 \mathrm{~cm}$ small particle size aggregate open-graded asphalt mixture was paved. After being cured at $25^{\circ} \mathrm{C}$ for $7 \mathrm{~d}$, the core specimens with a diameter of $10 \mathrm{~cm}$ were drilled from the composite structure. Finally, the core specimens were kept at $25^{\circ} \mathrm{C}, 40^{\circ} \mathrm{C}$, and $60^{\circ} \mathrm{C}$ in the constant temperature ovens for $4 \mathrm{~h}$, respectively, and then the direct shear test was carried out by using the direct shear apparatus of Chang'an University, and the shear rate was $10 \mathrm{~mm} / \mathrm{min}$.

(2) Test Method of WEA Composition and Spraying Amount Determination. The key component of WEA bonding material is WER. The content of WER directly affects the hightemperature stability and durability of the WEA bonding layer. At the same time, the spraying amount of WEA also affects the interlaminar bonding performance, so it is necessary to carry out the study on the composition and spraying amount of WEA. At present, when the WEA was used as the interlaminar bonding material in the road engineering field, the content of WER was generally $15-25 \%$, and its spraying amount was $0.6-1.2 \mathrm{~kg} / \mathrm{m}^{2}[27,28]$. In this study, the content of WER was set at three levels of $15 \%$, $20 \%$, and $25 \%$. The spraying amount of WEA was set at three levels of $0.6 \mathrm{~kg} / \mathrm{m}^{2}, 0.8 \mathrm{~kg} / \mathrm{m}^{2}$, and $1.0 \mathrm{~kg} / \mathrm{m}^{2}$. According to the determined aggregate spreading and interlaminar bonding materials spraying scheme, the friction course composite structure specimens were prepared and cured. The interlaminar shear strength of the composite structure was tested to optimize the composition and spraying amount of WEA bonding material.

2.3.3. Test Method of the Open-Graded Asphalt Mixture Construction Time Determination. To determine the effect of the open-graded asphalt mixture construction time on interlaminar bonding performance, two schemes were designed to prepare the friction course composite structure specimen. One is to pave the open-graded asphalt mixture immediately after the bonding material was spraying, and the other is to pave the open-graded asphalt mixture after the WEA was emulsified and dried. The construction time of the open-graded asphalt mixture was determined by comparing the interlaminar shear strength of the composite structure specimens. The test specimens were prepared according to the aggregate spreading scheme, the composition, and spraying amount of WEA determined in this study. In addition to the paving time of the open-graded asphalt mixture, the structure and size of the specimen, the fabrication, and the performance test method were the same as the bonding layer optimization test method in Section 2.3.2.

\subsubsection{Test Method of the Open-Graded Friction Course Road} Performance and Durability. According to the optimized asphalt aggregate ratio of the open-graded asphalt mixture and bonding layer scheme, the friction course composite structure specimens composed of $3 \mathrm{~cm} \mathrm{AC-13}$ asphalt mixture + bonding layer $+2 \mathrm{~cm}$ small particle size aggregate open-graded asphalt mixture $(30 \mathrm{~cm} \times 30 \mathrm{~cm})$ were prepared. According to JTG E20-2011, China [30], and Field Test Methods of Highway Subgrade and Pavement (JTG 3450-2019), China [31], the road performance of the friction course was tested. The $60^{\circ} \mathrm{C}$ dynamic stability of the rutting test was used to evaluate its high-temperature stability. The drainage performance of the friction course was evaluated by measuring the permeability coefficient with pavement seepage meter. The antisliding performance of the friction course was evaluated by the British Pendulum Number. The water stability of the friction course was evaluated by the immersion Marshall stability, the immersion Cantabro mass loss, and the immersion interlaminar shear strength. Through the loading wear test of the four-wheel wear tester of Chang'an University, the wear resistance of the friction course was evaluated by cumulative wear mass loss rate and cumulative wear depth, and the interlaminar shear strength of the friction course after loading wear was tested to evaluate the interlaminar bonding durability.

(1) Water Stability Test. Before the immersion Marshall stability test, the standard Marshall specimens were placed in a $60 \pm 1^{\circ} \mathrm{C}$ constant temperature water tank for $48 \mathrm{~h}$. Then the Marshall stability was tested on the Marshall stability meter. Before the immersion Cantabro test, the standard Marshall specimens were placed in a $60 \pm 1^{\circ} \mathrm{C}$ constant temperature water tank for $48 \mathrm{~h}$. Then the specimens were taken out and placed at $25^{\circ} \mathrm{C}$ for $24 \mathrm{~h}$. The subsequent test was carried out according to the Cantabro test method. Before the immersion interlaminar shear test, the $10 \mathrm{~cm}$ core specimens of the composite specimen were immersed in a $25 \pm 1^{\circ} \mathrm{C}$ constant temperature water tank for $48 \mathrm{~h}$, and then the direct shear test was carried out at $25^{\circ} \mathrm{C}$ by using the direct shear apparatus.

(2) Durability Test. The friction course composite structure specimens were prepared and cured at $25^{\circ} \mathrm{C}$ for $7 \mathrm{~d}$. Then the wear test was carried out at $25^{\circ} \mathrm{C}$. Polyurethane tire $(20 \mathrm{~cm}$ in diameter and $5 \mathrm{~cm}$ in width) with good wear resistance and shore hardness of 70-75 A was selected as the test wheel. The test wheel pressure was $0.7 \mathrm{MPa}$. The wear depth of the specimen by the test wheel was tested once for each increase in the number of loading wear 5000 times, and the mass of the specimen after loading wear was weighed to calculate the cumulative mass loss rate. The total loading wear time was set to 100000 times. After 100000 times of loading wear, the core specimen with a diameter of $10 \mathrm{~cm}$ was drilled. The interlaminar shear strength was tested to evaluate the durability of interlaminar bonding performance. The test process is shown in Figure 1.

\section{Results and Discussion}

3.1. The Basic Properties of the Open-Graded Asphalt Mixture. According to the set asphalt aggregate ratio, the basic properties of the small particle size aggregate open-graded asphalt mixture were tested. The test results of Cantabro 

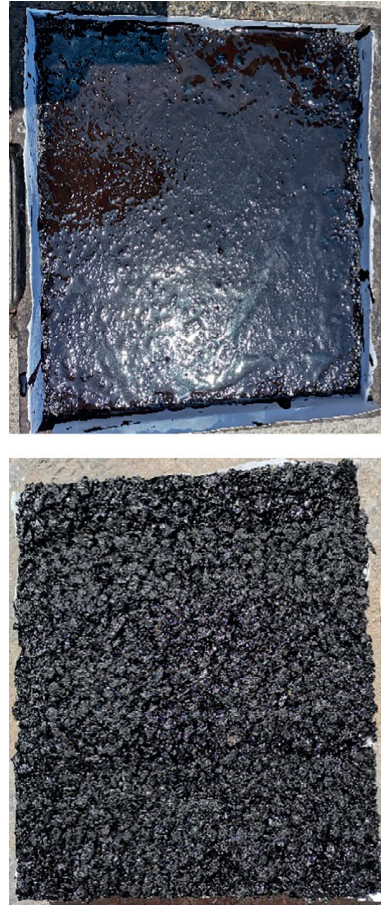

(a)

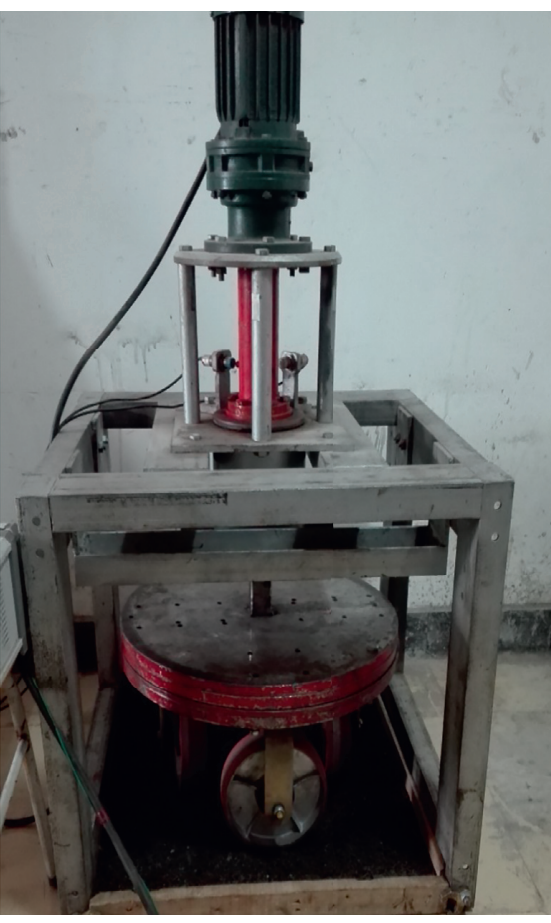

(b)
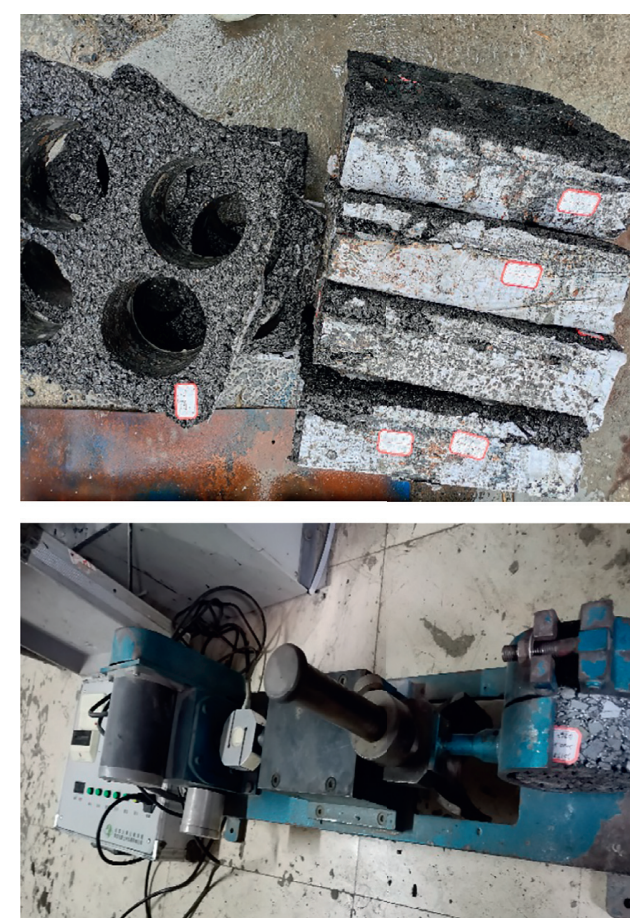

(c)

Figure 1: Durability test. (a) Specimen preparation. (b) Wear test. (c) Direct shear test.

mass loss, binder drainage mass, percent air voids, and Marshall stability are shown in Figure 2.

It can be seen from Figure 2 that, with the increase of asphalt aggregate ratio, the Cantabro mass loss of the opengraded asphalt mixture gradually decreased, and the spalling resistance improved continuously. The binder drainage mass of the mixture increased gradually, but it was still less than $0.12 \%$. According to the Cantabro mass loss and binder drainage mass of the mixture, it is suggested that the asphalt aggregate ratio of the open-graded asphalt mixture should not be less than $5 \%$.

To ensure the drainage performance of the friction course, the open-graded asphalt mixture should have a certain percent of air voids, especially percent connected air voids. With the increase of the asphalt aggregate ratio, the percent air voids and percent connected air voids of the mixture first increased and then decreased, and both of them reached the maximum value when the asphalt aggregate ratio was $5 \%$, which were $22.3 \%$ and $16.5 \%$, respectively. It is suggested that the asphalt aggregate ratio of the small particle size aggregate open-graded asphalt mixture should not be greater than $6 \%$.

The Marshall stability was used to evaluate the structural strength of the mixture. With the increase of the asphalt aggregate ratio, the Marshall stability of the mixture increased first and then decreased, and the flow value increased gradually. The Marshall stability reached the maximum value when the asphalt aggregate ratio was $5.5 \%$, which was $6.57 \mathrm{KN}$. To ensure the strength of the friction course, it is suggested that the asphalt aggregate ratio should not be less than $5 \%$.
Considering the spalling resistance, percent air voids, and structural strength of the open-graded asphalt mixture, the asphalt aggregate ratio of the small particle size aggregate open-graded asphalt mixture is recommended to be $5.0-5.5 \%$.

3.2. The Bonding Layer Optimization. To improve the service quality and durability of the ultrathin OGFC, WEA was selected as the interlaminar bonding material to optimize the bonding performance between the friction course and the underlying layer. Through testing the interlaminar shear strength of the friction course composite structure specimen, it was determined whether it is necessary to spread aggregate between layers. The composition and spraying amount of WEA interlaminar bonding material were recommended.

\subsubsection{The Effect of Spreading Aggregate on the Interlaminar} Bonding Performance. At each test temperature, the interlaminar shear strength of the composite structure specimens of spreading aggregate and nonspreading aggregate was tested. The results are shown in Figure 3.

It can be seen from Figure 3 that the interlaminar shear strength of the composite structure specimens prepared with different interlaminar bonding materials decreased in varying degrees with the increase of test temperature. The analysis showed that the asphalt material softened continuously with the increase of temperature, so that the bonding performance decreased. At each test temperature, the interlaminar shear strength of WEA was better than that of 


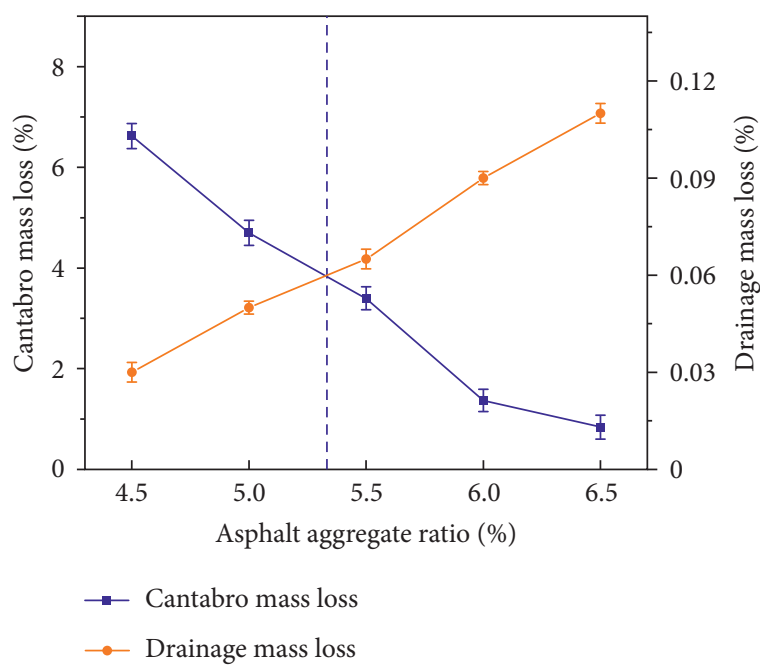

(a)

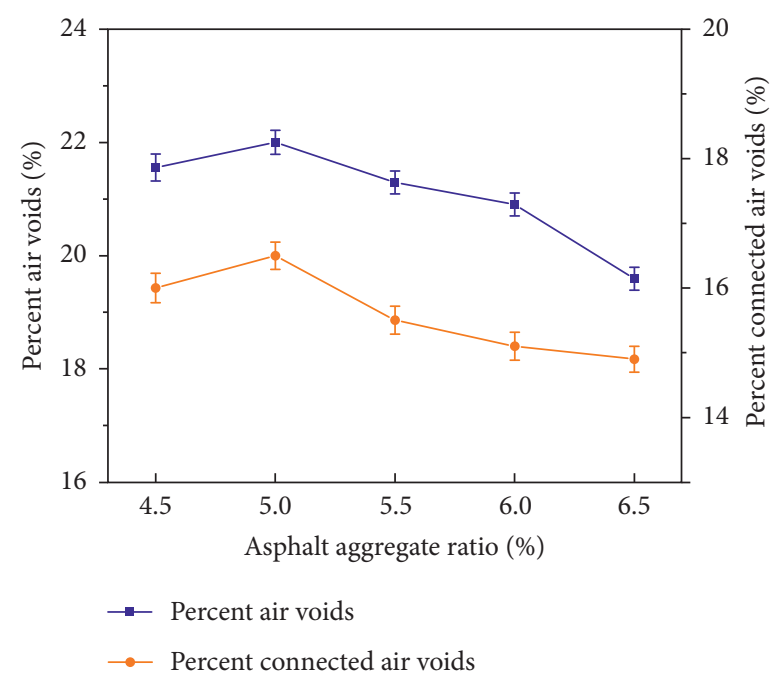

(b)

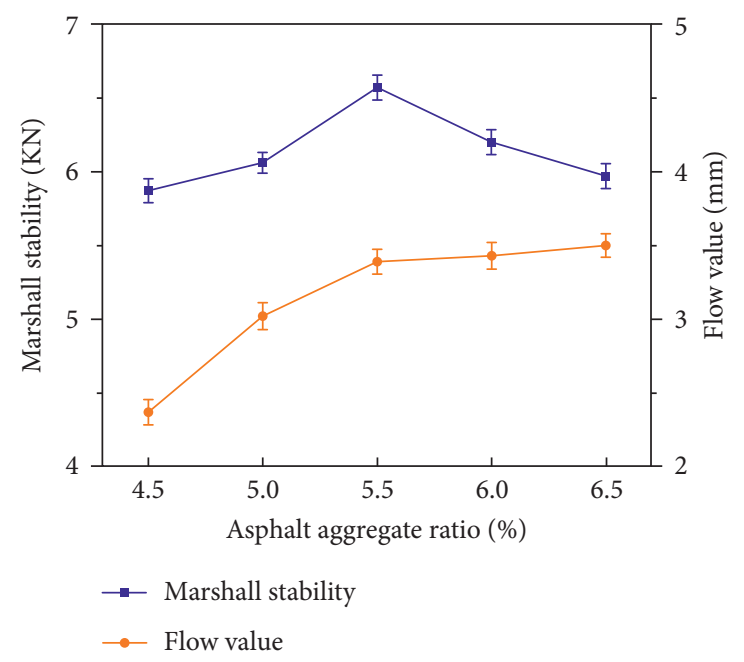

(c)

FIGURE 2: The basic performance of open-graded asphalt mixture: (a) Cantabro mass loss and binder drainage mass; (b) percent air voids and percent connected air voids; (c) Marshall stability and flow value.

HVA and SBS-modified asphalt bonding materials, showing better interlaminar bonding performance.

When HVA and SBS-modified asphalt were used as interlaminar bonding materials, the $60^{\circ} \mathrm{C}$ interlaminar shear strength of the bonding layer spreading aggregate was higher than that of nonspreading aggregate, but the $25^{\circ} \mathrm{C}$ and $40^{\circ} \mathrm{C}$ interlaminar shear strength of the bonding layer spreading aggregate were lower than that of nonspreading aggregate. At each test temperature, the interlaminar shear strength of the WEA bonding layer spreading aggregate was about 0.03-0.07 MPa lower than that of nonspreading aggregate. The analysis shows that spreading aggregate reduced the contact area between open-graded asphalt mixture and interlaminar bonding material, which leads to the decrease of interlaminar bonding performance. Therefore, in this paper, WEA was used as the interlaminar bonding material, and the bonding layer scheme of nonspreading aggregate was selected.
3.2.2. WEA Composition and Spraying Amount Determination. To improve the interlaminar bonding performance between the friction course and the underlying layer, the influence of the composition and spraying amount of WEA bonding material on the interlaminar bonding performance was studied. The interlaminar shear strength test results are shown in Figure 4.

From Figure 4 that, with the increase of the WER content, the interlaminar shear strength of the WEA bonding layer increased gradually. The interlaminar shear strength increased by $0.05-0.2 \mathrm{MPa}$ when the WER content increased from $15 \%$ to $20 \%$, while the interlaminar shear strength increased little when the WER content increased from $20 \%$ to $25 \%$. It may be because when the WER content was low, with the increase of WER content, the interpenetrating network structure of asphalt and epoxy resin gradually formed, and the interlaminar bonding performance increased. With the continuous increase of epoxy 


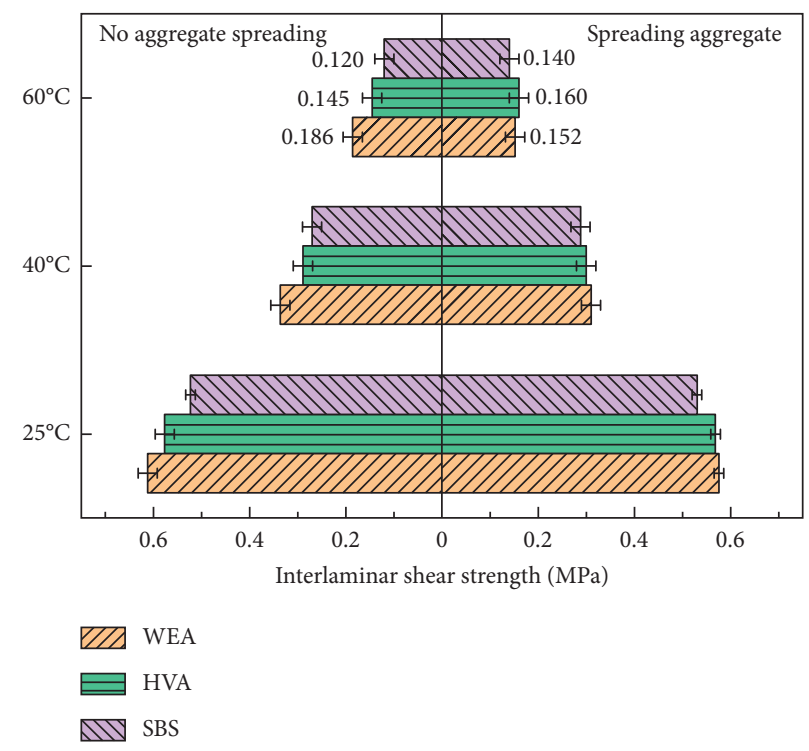

FIGURE 3: The effect of spreading aggregate on the interlaminar bonding performance.

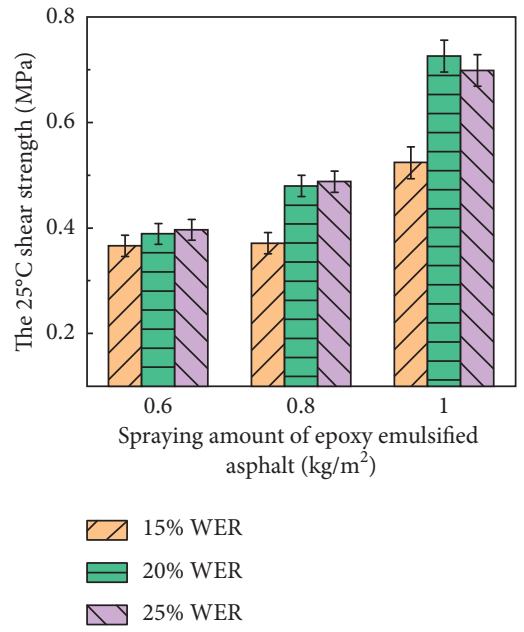

(a)

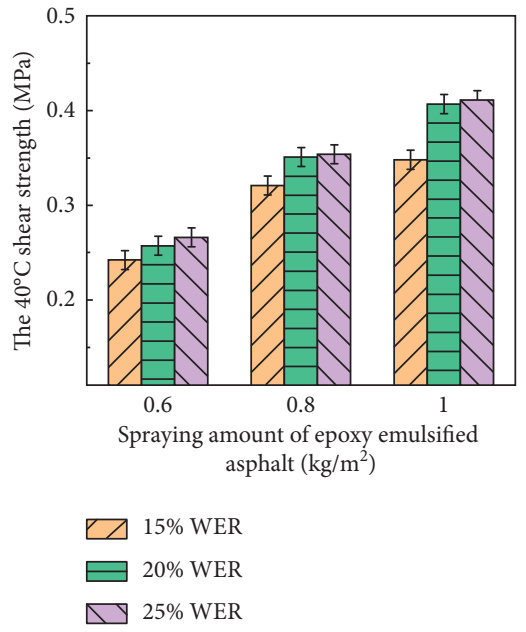

(b)

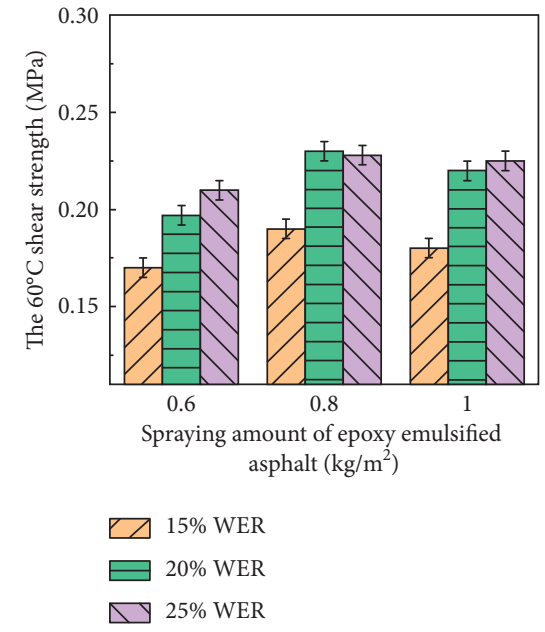

(c)

Figure 4: The interlaminar shear strength of the WEA bonding layer: (a) $25^{\circ} \mathrm{C}$; (b) $40^{\circ} \mathrm{C}$; (c) $60^{\circ} \mathrm{C}$.

resin content, there was epoxy resin, which did not form network structure with asphalt, and the growth of bonding performance was no longer obvious. Therefore, it is suggested that the content of WER in WEA bonding material was $20 \%$.

At the test temperature of $25^{\circ} \mathrm{C}$ and $40^{\circ} \mathrm{C}$, with the increase of the WEA spraying amount, the interlaminar shear strength increased gradually. When the content of WER was $20 \%$ and the spraying amount was $1 \mathrm{~kg} / \mathrm{m}^{2}$, the interlaminar shear strength reaches the maximum value, which was $0.726 \mathrm{MPa}$. At a high temperature of $60^{\circ} \mathrm{C}$, with the increase of its spraying amount, the interlaminar shear strength increased first and then decreased. The maximum value was obtained at the spraying amount of $0.8 \mathrm{~kg} / \mathrm{m}^{2}$. Considering the interlaminar bonding performance of WEA at different temperatures, it is suggested that the spraying amount of WEA was $1 \mathrm{~kg} / \mathrm{m}^{2}$.

\subsection{The Open-Graded Asphalt Mixture Construction Time} Determination. To determine the effect of the open-graded asphalt mixture construction time on interlaminar bonding performance, the friction course composite structure specimens of the two schemes were prepared. Their interlaminar shear strength test results are shown in Figure 5.

It can be seen from Figure 5 that when WEA was used as interlaminar bonding material, its interlaminar shear strength under the condition of synchronous construction of open-graded asphalt mixture was about $0.05-0.10 \mathrm{MPa}$ higher than that of asynchronous construction. Under the 


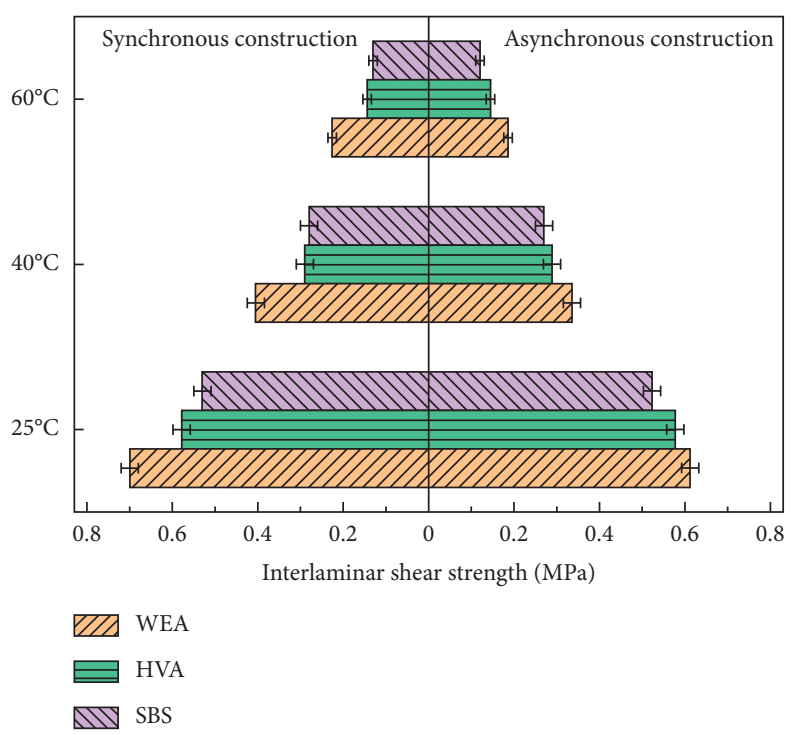

FIGURE 5: The effect of asphalt mixture construction time on the interlaminar bonding performance.

condition of synchronous construction, the interlaminar shear strength of the WEA bonding layer was $0.09-0.17 \mathrm{MPa}$ higher than that of HVA and SBS-modified asphalt bonding material. The analysis showed that after the WEA was sprayed, the epoxy resin in it gradually solidified with the evaporation of water in the curing process. The epoxy resin is thermosetting, and some of them were irreversible after curing, which led to the decrease of bonding performance. Therefore, it is recommended to pave the open-graded asphalt mixture immediately after the WEA bonding material was sprayed.

\subsection{The Road Performance and Durability of the Friction} Course. Based on the optimized asphalt aggregate ratio of the open-graded asphalt mixture and bonding layer scheme, the friction course composite structure specimens were prepared. The high-temperature stability, skid resistance, drainage, and water stability performance of the friction course were comprehensively evaluated. The wear resistance of the friction course and the interlaminar bonding durability were studied.

3.4.1. The Road Performance of the Friction Course. The high-temperature stability, antisliding performance, drainage performance, water stability performance, and interlaminar bonding water stability of the friction course were comprehensively tested, and the results are shown in Figure 6.

It can be seen from Figure 6(a) that when the asphalt aggregate ratio was $5.5 \%$, the dynamic stability of the friction course reached the maximum value, which was 7180 times/ $\mathrm{mm}$. It was obviously higher than the requirement of 3500 times/mm specified in CJJ/T 190-2012, China [29], showing good high-temperature stability. The British Pendulum Number of the friction course was higher than 69 BPN. It shows good antisliding performance and can effectively recover the antisliding function of the old pavement. With the increase of asphalt aggregate ratio, the water permeability coefficient of the friction course gradually decreased, but it was still higher than $800 \mathrm{~mL} / 15 \mathrm{~s}$ specified in $C J J / T$ 190-2012, China [29]. It can improve the driving safety under the slippery condition.

It can be seen from Figure 6(b) that when the asphalt aggregate ratio was $5.5 \%$, the immersion Marshall stability of the friction course reached the maximum value, which was $6.25 \mathrm{kN}$. The immersion residual Marshall stability ratio was 95.4\%. Compared with the Cantabro mass loss, the immersion Cantabro mass loss showed a certain increase, but it was still lower than $5.3 \%$, showing good water stability performance.

It can be seen from Figure 6(c) that the interlaminar shear strength of the friction course composite structure prepared by the three kinds of interlaminar bonding materials decreased to different degrees after immersion treatment. The $25^{\circ} \mathrm{C}$ interlaminar shear strength of the WEA bonding layer was $0.665 \mathrm{MPa}$ after immersion treatment. The interlaminar bonding performance of WEA was still better than that of HVA and SBS-modified asphalt. After immersion treatment, the interlaminar shear strength retention rate of the WEA bonding layer was the highest, followed by HVA. The WEA bonding layer shows better immersion bonding performance and water stability. It can better guarantee the service quality and durability of the friction course.

3.4.2. The Durability of the Friction Course. Through the loading wear test, the wear resistance of the friction course was evaluated by cumulative wear mass loss rate and $\mathrm{cu}-$ mulative wear depth. The interlaminar shear strength of the friction course after loading wear was tested to evaluate the interlaminar bonding durability. The results are shown in Figure 7. 


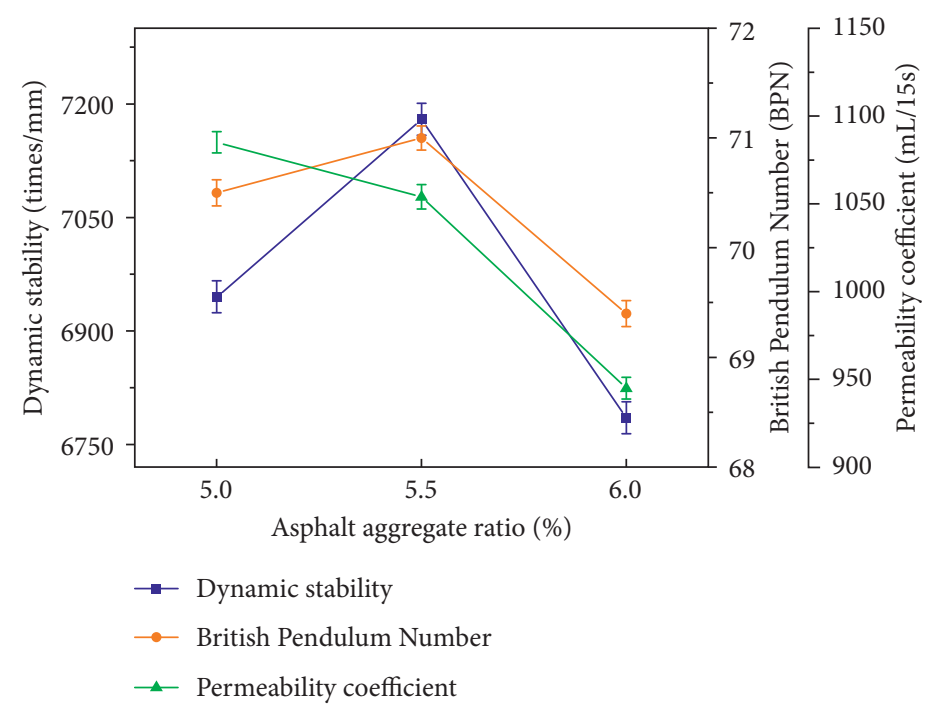

(a)

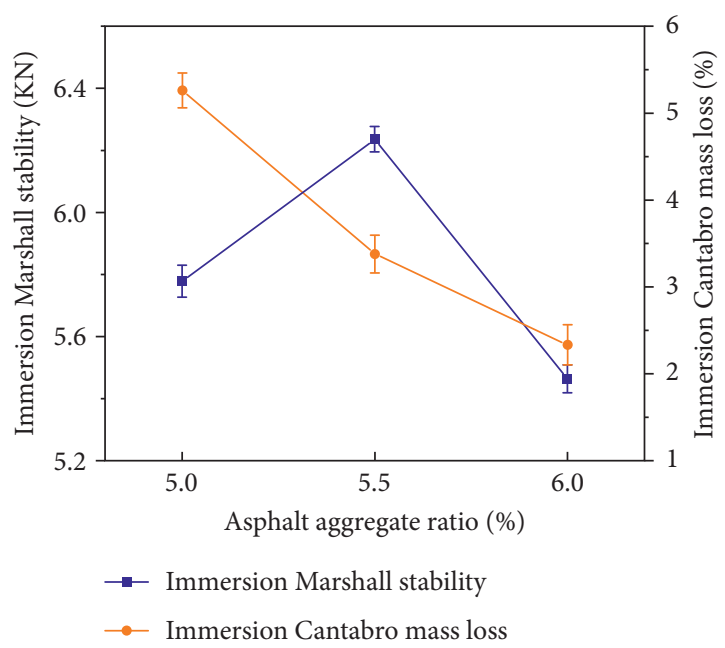

(b)

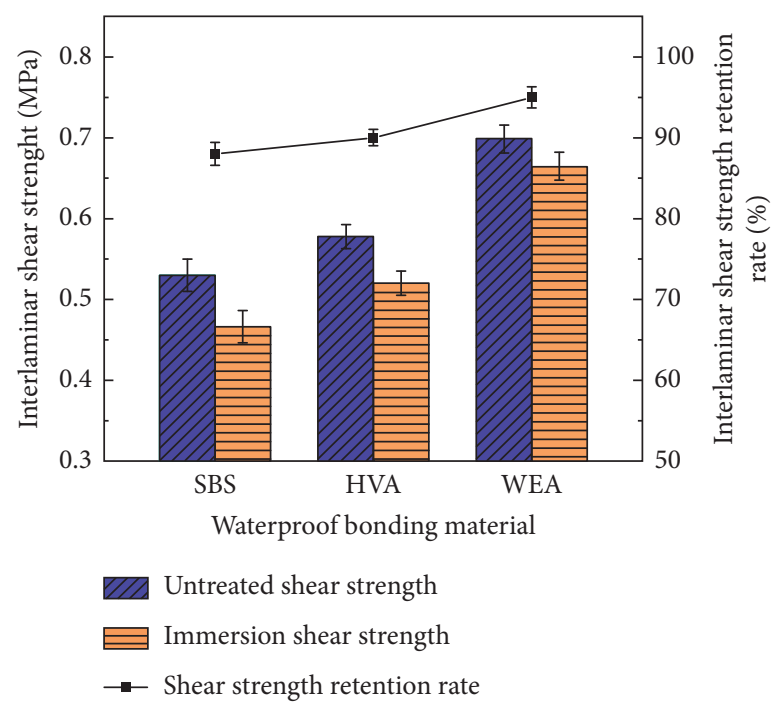

(c)

Figure 6: The road performance of the friction course: (a) dynamic stability, British Pendulum Number and permeability coefficient; (b) immersion Marshall stability and Cantabro mass loss; (c) immersion interlaminar shear strength.

Analysis of Figure 7(a) showed that, as the wear times of loading wear increased, the cumulative wear mass loss rate and cumulative wear depth of the friction course gradually increased. In the initial stage of loading wear, the cumulative wear mass loss rate and cumulative wear depth increased rapidly. With the continuous increase of wear times, the growth of the wear mass loss and wear depth tended to be stable gradually. In the initial stage of loading wear, the friction course was gradually compacted, which made the wear depth increase rapidly, and then gradually tended to be stable. After 100000 times of loading wear, the cumulative wear mass loss rate and cumulative wear depth of the friction course were $2.3 \%$ and $1.2 \mathrm{~mm}$, respectively, both of them were at a low level. The friction course still had sufficient percent air voids and texture depth to ensure its drainage and antisliding performance. It shows that the friction course has a good antiwear performance.

It can be seen from Figure 7(b), the interlaminar shear strength of the three kinds of bonding layer decreased to some extent after 100000 times of loading wear. The interlaminar shear strength of the WEA bonding layer was still higher than that of HVA and SBS-modified asphalt. The interlaminar shear strength retention rate of the WEA bonding layer was the highest after loading wear, followed by HVA. With the increase of test temperature, the interlaminar bonding durability of each bonding layer gradually decreased. But the interlaminar shear strength retention rate of the WEA bonding layer was more than $89 \%$. It shows 


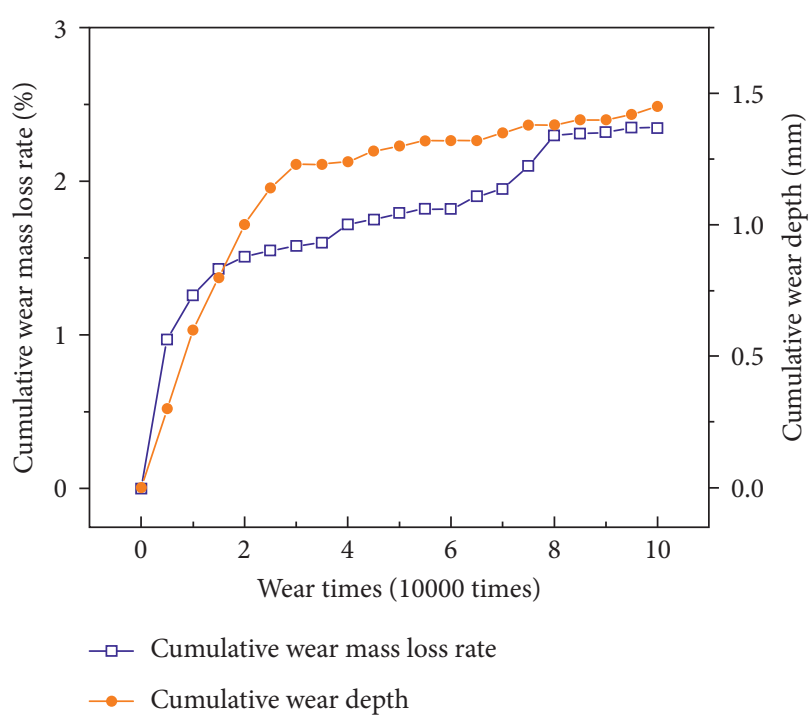

(a)

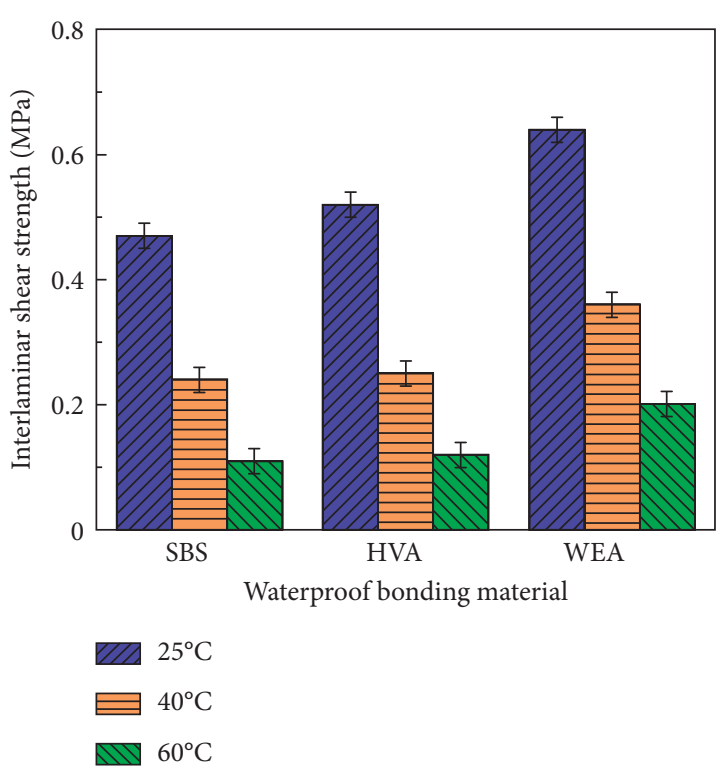

(b)

FiguRE 7: The durability of the friction course: (a) the wear resistance; (b) interlaminar shear strength after loading wear.

better interlaminar bonding durability. WEA can be used as the interlaminar bonding material of open-graded friction course.

\section{Conclusion}

(1) Considering the spalling resistance, percent air voids, and structure strength of the open-graded asphalt mixture, the asphalt aggregate ratio of the small particle size aggregate open-graded asphalt mixture is recommended to be $5.0-5.5 \%$.

(2) The interlaminar bonding performance of WEA bonding layer is better than that of HVA and SBSmodified asphalt bonding material. It is recommended that the open-graded asphalt mixture is paved immediately after WEA bonding material was sprayed, and the bonding layer does not spread aggregate.

(3) The suitable content of WER in WEA interlaminar bonding material is $20 \%$. It is suggested that the spraying amount of WEA bonding layer is $1 \mathrm{~kg} / \mathrm{m}^{2}$. The $25^{\circ} \mathrm{C}$ interlaminar shear strength is more than $0.726 \mathrm{MPa}$.

(4) The WEA bonding layer can effectively improve interlaminar bonding performance, water stability, and durability of the friction course. The friction course shows good antisliding, drainage, water stability, and wear resistance properties.

(5) In this paper, the WEA bonding layer for the opengraded friction course was optimized. The various road performances of the friction course were systematically studies. It is necessary to further study the bonding strength formation mechanism of WEA and the effect of loading wear on the pore structure of the friction course.

\section{Data Availability}

The data used to support the findings of this study are included within the article.

\section{Conflicts of Interest}

The authors declare that they have no conflicts of interest regarding the publication of this paper.

\section{Acknowledgments}

This research was sponsored by the Fundamental Research Funds for the Central Universities, CHD (300102211704 and 300102218304).

\section{References}

[1] Editorial Department of China Journal of Highway and Transport, "Review on China's pavement engineering research.2020," China Journal of Highway and Transport, vol. 33, no. 10, pp. 1-66, 2020, in Chinese.

[2] S. Luo, Z. Qian, and Y. Xue, "Performance evaluation of opengraded epoxy asphalt concrete with two nominal maximum aggregate sizes," Journal of Central South University, vol. 22, no. 11, pp. 391-397, 2015.

[3] G. L. Yang, C. H. Wang, P. H. Wen et al., "Performance characteristics of cold-mixed porous friction course with composite modified emulsified asphalt," Journal of Materials in Civil Engineering, vol. 32, no. 3, Article ID 04019372, 2019.

[4] E. Coleri, J. T. Harvey, K. Yang, and J. M. Boone, "Micromechanical investigation of open-graded asphalt friction courses' rutting mechanisms," Construction and Building Materials, vol. 44, pp. 25-34, 2013.

[5] E. Coleri, M. Kayhanian, J. T. Harvey, K. Yang, and J. M. Boone, "Clogging evaluation of open graded friction course pavements tested under rainfall and heavy vehicle 
simulators," Journal of Environmental Management, vol. 129, pp. 164-172, 2013.

[6] Y. Wang, Z. Leng, and G. Wang, "Structural contribution of open-graded friction course mixes in mechanistic-empirical pavement design," International Journal of Pavement Engineering, vol. 15, no. 8, pp. 731-741, 2014.

[7] E. Pasquini, F. Canestrari, F. Cardone, and F. A. Santagata, "Performance evaluation of gap graded Asphalt Rubber mixtures," Construction and Building Materials, vol. 25, no. 4, pp. 2014-2022, 2011.

[8] B. J. Eck, R. J. Winston, W. F. Hunt, and M. E. Barrett, "Water quality of drainage from permeable friction course," Journal of Environmental Engineering, vol. 138, no. 2, pp. 174-181, 2012.

[9] M. E. Barrett, P. Kearfott, and J. F. Malina, "Stormwater quality benefits of a porous friction course and its effect on pollutant removal by roadside shoulders," Water Environment Research, vol. 78, no. 11, pp. 2177-2185, 2006.

[10] M. Zeng, L. Peng, C. Wu et al., "Experimental study of the performance of ultrathin asphalt friction course," Journal of Wuhan University of Technology, vol. 34, no. 4, pp. 27-31, 2012, in Chinese.

[11] R. Hafezzadeh and A. Kavussi, "Application of microsurfacing in repairing pavement surface rutting," Road Materials and Pavement Design, pp. 1-12, 2019.

[12] X. Ji, Y. Hou, H. Zou, B. Chen, and Y. Jiang, "Study of surface microscopic properties of asphalt based on atomic force microscopy," Construction and Building Materials, vol. 242, Article ID 118025, 2020.

[13] X. Ji, E. Sun, H. Zou, Y. Hou, and B. Chen, "Study on the multiscale adhesive properties between asphalt and aggregate," Construction and Building Materials, vol. 249, Article ID 118693, 2020.

[14] W. Jiang, D. Yuan, J. Shan, W. Ye, H. Lu, and A. Sha, "Experimental study of the performance of porous ultra-thin asphalt overlay," International Journal of Pavement Engineering, p. 1, 2020.

[15] J. Yu, X. Zhang, and C. Xiong, “A methodology for evaluating micro-surfacing treatment on asphalt pavement based on grey system models and grey rational degree theory," Construction and Building Materials, vol. 150, pp. 214-226, 2017.

[16] Q. Zhang, Y.-h. Xu, Z.-g. Wen et al., "Influence of water-borne epoxy resin content on performance of waterborne epoxy resin compound SBR modified emulsified asphalt for tack coat," Construction and Building Materials, vol. 153, pp. 774-782, 2017.

[17] C. Wang, X. Xiao, Y. Lu, C. Shu, and J. Guo, "Utilization and properties of modified epoxy resin for colorful anti-slip pavements," Construction and Building Materials, vol. 227, Article ID 116801, 2019.

[18] Q. Chen, S. Wang, C. Wang et al., "Modified waterborne epoxy as a cold pavement binder: preparation and long-term working properties," Journal of Materials in Civil Engineering, p. 33, 2021.

[19] Q. Chen, Y. Lu, C. Wang, B. Han, and H. Fu, "Effect of raw material composition on the working performance of waterborne epoxy resin for road," International Journal of Pavement Engineering, p. 1, 2020.

[20] Y. Gu, B. Tang, L. He, F. Yang, H. Wang, and J. Ling, "Compatibility of cured phase-inversion waterborne epoxy resin emulsified asphalt," Construction and Building Materials, vol. 229, Article ID 116942, 2019.

[21] Y. Cao, A. Sha, Z. Liu, J. Li, and W. Jiang, "Energy output of piezoelectric transducers and pavements under simulated traffic load," Journal of Cleaner Production, vol. 279, Article ID 123508, 2021.

[22] Q. Xiang and F. Xiao, "Applications of epoxy materials in pavement engineering," Construction and Building Materials, vol. 235, Article ID 117529, 2020.

[23] J. Ji, L. H. Liu, Z. Suo et al., "Performances of micro-surfacing with waterborne epoxy resin modified emulsified asphalt," Journal of Chang'an University(Natural Science Edition), vol. 37, no. 5, pp. 23-30, 2017, in Chinese.

[24] R. Li, Z. Leng, Y. Zhang, and X. Ma, "Preparation and characterization of waterborne epoxy modified bitumen emulsion as a potential high-performance cold binder," Journal of Cleaner Production, vol. 235, pp. 1265-1275, 2019.

[25] S. Han, T. Yao, X. Han, Z. Hongwei, and X. Yang, "Performance evaluation of waterborne epoxy resin modified hydrophobic emulsified asphalt micro-surfacing mixture," Construction and Building Materials, vol. 249, Article ID 118835, 2020.

[26] C. Hu, J. Zhao, Z. Leng, M. N. Partl, and R. Li, "Laboratory evaluation of waterborne epoxy bitumen emulsion for pavement preventative maintenance application," Construction and Building Materials, vol. 197, pp. 220-227, 2019.

[27] M. Liu, S. Han, J. Pan, and W. Ren, "Study on cohesion performance of waterborne epoxy resin emulsified asphalt as interlayer materials," Construction and Building Materials, vol. 177, pp. 72-82, 2018.

[28] G. L. Yang, C. H. Wang, H. Fu et al., "Waterborne epoxy resin/ polyurethane/emulsified asphalt: preparation and properties [J]," Journal of Materials in Civil Engineering, vol. 31, no. 11, Article ID 04019265, 2019.

[29] Chang'an University, Technical Specification for Permeable Asphalt Pavement (CJJ/T 190-2012), Ministry of Housing and Urban-Rural Construction of the People's Republic of China, Beijing, China, 2012, in Chinese.

[30] Highway Research Institute of the Transportation Department, Standard Test Methods of Bitumen and Bituminous Mixtures for Highway Engineering (JTG E20-2011), Ministry of transport of the People's Republic of China, Beijing, China, 2011, in Chinese.

[31] Highway Research Institute of the Transportation Department, Field Test Methods of Highway Subgrade and Pavement (JTG 3450-2019), Ministry of Transport of the People's Republic of China, Beijing, China, 2019, in Chinese. 